\title{
GEOGRAFIA E NAZISMO: UMA CARACTERIZAÇÃO DO CONCEITO DE ESPAÇO VITAL (LEBENSRAUM) DURANTE O REGIME NAZISTA
}

\author{
Antonio Carlos Vitte (PQ), Rafael Bueno de Oliveira (IC).
}

\section{Resumo}

O conceito de Lebensraum, ou espaço vital, foi formulado pelo geógrafo alemão Friedrich Ratzel (1844 1904) no contexto da unificação alemã e no momento da II Revolução Industrial (século XIX). O conceito de Lebensraum foi posteriormente apropriado pelo regime nazista, utilizando-o como matriz ideológica para construir uma nação germânica, mas principalmente para justificar o seu expansionismo no leste europeu, durante a Segunda Guerra Mundial (1939-1945).

Palavras Chave: Lebensraum, nazismo, geografia.

\section{Introdução}

O conceito de Lebensraum (Espaço Vital), foi desenvolvido pelo geógrafo alemão Friedrich Ratzel (1844-1904) e diz respeito a uma certa proporção de equilíbrio entre a população de uma sociedade e os recursos naturais disponíveis para suprimento de suas necessidades (MORAES, 2007).

\section{Resultados e Discussão}

A partir dos resultados obtidos pode se observar que a apropriação do conceito de Lebensraum (Espaço Vital), pelo regime nazista, se deu de forma prática, devido as políticas de anexação do início da Segunda Guerra Mundial (1939 -1945). Entretanto este conceito quando da sua concepção, foi puramente teórico e acadêmico. Para se chegar nos resultados obtidos por esta pesquisa, foram diversas fontes durante a revisão bibliográfica, pautada em livros e periódicos.

\section{Conclusões}

Com a realização deste trabalho pode se concluir que o conceito de Lebensraum (Espaço Vital) e sua apropriação por Hitler, serviu para o propósito político e econômico do III Reich, por ter inaugurado uma nova era durante a Segunda Guerra Mundial e guerras modernas.

\section{Agradecimentos}

Gostaria de agradecer, a Universidade Estadual de Campinas, por me contemplar com o projeto e os meios necessários para a realização deste. Gostaria também de agradecer ao meu orientador Antonio Carlos Vitte, pela paciência e dedicação neste período de pesquisa e aos meus pais pelo apoio em toda e qualquer situação.

CLAVAL, Paul. La evolucíon de la geografia humana. Madrid: Oikos-Tau, 1985.

COSTA, Wanderley M. da (2010) Geografia Política e Geopolítica (Cap. 1, pp. 31-41), Editora Edusp, São Paulo S.P. WOODRUFF, Smith. Politics and the Sciences Of Culture in Germany, 1840-1920, Oxford Unity Press. 